\title{
Sourdough bread preparation using selected lactic acid bacterial starter cultures
}

\author{
Nandini Math, K. S. Jagadeesh*, Shakuntala Masur ${ }^{1}$ and Pushpa Bharati ${ }^{1}$ \\ Department of Agricultural Microbiology, University of Agricultural Sciences, Dharwad 580 005, INDIA \\ ${ }^{1}$ Department of Food Science and Nutrition, University of Agricultural Sciences, Dharwad 580 005, INDIA \\ *Corresponding author. E-mail: jagsbio@gmail.com
}

Received: May 18, 2014; Revised received: August 07, 2014 Accepted: October 03, 2014

\begin{abstract}
The lactic fermentation of cereals is known to improve the food quality through the development of flavor, enhancement of the nutritional value and shelf life, and by removing toxic or antinutritional factors of food products. Lactic acid bacteria (LAB) strains are able to improve the shelf life of several food products. The efficiency of the LAB cultures determined in in vitro assays was confirmed in bread manufacture. The sourbread prepared using 50 per cent yeast and 50 per cent LAB starter (based on cell density) was found to be superior to the conventional bread in textural characteristics, flavor, appearance and even taste. It contained enough protein $(10.15 \%)$ and the least fat value (7.68\%). It scored the highest acceptability index of 81.70 . These results point out the advantages of using selected LAB strains as starter cultures for sourdough fermentation.
\end{abstract}

Keywords: Bread, Lactic acid bacteria, Nutritional profile, Sensory characters, Sourdough, Starter culture

\section{INTRODUCTION}

Lactic acid bacteria (LAB) have a long history in preserving foods from spoilage microorganisms, they are commonly used in food fermentation, produce several metabolites with beneficial health effects and thus, are generally recognized as safe (GRAS) Diop et al. 2007). For several thousands of years, bread has been one of the major constituents of the human diet, making the baking of yeast-based breads one of the oldest biotechnological processes. Sourdough is an intermediate product between dough and traditional bread preparation, containing flour, water and metabolically active microorganisms, mainly lactic acid bacteria (LAB) and yeast. During sourdough fermentation, lactic acid bacteria (LAB) produce a number of metabolites which have been shown to have a positive effect on the texture and staling of bread (Tieking and Gänzle, 2005). Exopolysaccharides (EPS) produced by LAB have the potential to replace more expensive hydrocolloids used as bread improvers. Organic acids affect the protein and starch fractions of flour. Additionally, the drop in $\mathrm{pH}$ associated with acid production causes an increase in the protease and amylase activities of the flour, thus leading to a reduction in staling. While improving the textural qualities of bread, sourdough fermentation also results in increased mineral bioavailability and reduced phytate content (Lopez et. al., 2000). Recent results have demonstrated the effectiveness of sourdough fermentation (Petra Gereková, 2011). The sourdoughs fermented with the hetero fermentative Lactobacillus spp. had higher acid equivalents, lower $\mathrm{pH}$-values and also gave bread with stronger taste of acidity and acetic acid than those fermented with the homo fermentative organisms. The sourdough bread was shown to have a stronger taste of acidity and also a more aromatic and crispy crust. The bread baked with sourdoughs fermented with the heterofermentative organisms, showed the best ability even to prevent growth of the mould, Eurotium rubrum (Paola Lavermicocca, 2000). Keeping these in view, the present investigation was conducted to prepare sourdough bread using selected lactic acid bacterial starter cultures.

\section{MATERIALS AND METHODS}

The Department of Agricultural Microbiology, UAS, Dharwad has a large collection of lactic acid bacteria, isolated from diverse sources. These isolates were screened for production of $\mathrm{CO}_{2}$, lactic acid and exopolysaccharides (EPS), and the potent strains selected. Refined wheat flour, sugar, salt, vanaspati and baker yeast (Saccharomyces cerevisae) were procured from the local market of Dharwad.

Testing the LAB isolates for functional traits: All the 22 isolates were tested for production of $\mathrm{CO}_{2}$ (Zuniga et al., 1993), lactic acid (Zuniga et al., 1993) and EPS (Garcia and Marshall, 1991). Based on these values, promising isolates were selected for sourbread preparation.

LAB strains used for bread preparation: Three LAB strains were used for bread preparation. They were LAB 49, LAB 72 and LAB 74. They were 
individually grown in de Man, Rogosa and Sharpe (MRS) broth medium for three days, centrifuged and a suspension prepared and mixed at 1:1:1: ratio (based on the cell population).

Preparation of bread: Maida $(1 \mathrm{~kg})$ was mixed with yeast $(20 \mathrm{~g})$, vanaspati (100 g) and sugar solution $(200 \mathrm{~g}$ in $600 \mathrm{ml})$. A table spoon of salt was added to maida flour and kneading done for $30 \mathrm{~min}$ to get a dough having a consistency suitable for producing a good textured bread. The kneaded dough was kept for raising (proofing) for $45 \mathrm{~min}$. The raised dough was filled in to a mould, pressed and incubated for $60 \mathrm{~min}$. The bread was baked by keeping the dough tins in an oven at $400^{\circ} \mathrm{F}\left(205^{\circ} \mathrm{C}\right)$ temperature for $30 \mathrm{~min}$., depanned, allowed to cool for $4 \mathrm{~h}$, sliced and packed in polythene bags.

The bread was prepared by using the following treatments. Yeast and LAB cultures were taken at different ratios. This was based on the cell density of the yeast used $\left(10^{8} \mathrm{cfu} / \mathrm{g}\right)$.

$\mathrm{T}_{1}-100 \%$ Yeast (present practice), $\mathrm{T}_{2}-50 \%$ Yeast + $50 \% \mathrm{LAB}, \mathrm{T}_{3}-50 \%$ Yeast and $\mathrm{T}_{4}-100 \%$ Yeast $+50 \%$ LAB.

Sensory evaluation of bread: The bread was prepared as above and subjected for sensory evaluation for appearance, color, texture, flavor and taste by hedonic score system as described by Meilgaard et al. (2007). For sensory evaluation of the bread, as many as 30 panelists were selected covering faculties from teaching, research and extension wings.

Nutritional analysis: The bread was analyzed for moisture, protein, fat, ash and crude fibre content (AACC, 2000).

\section{RESULTS AND DISCUSSION}

Table 1. reveals that many $\mathrm{LAB}$ isolates produced $\mathrm{CO}_{2}$. Although all the isolates produced lactic acid, LAB 72 produced the highest value $(8.3 \%)$. Similarly, the highest EPS was produced by LAB $49(81.7 \mu \mathrm{g} / \mathrm{ml})$. LAB 74 produced higher amounts of both EPS (76.50 $\mu \mathrm{g} / \mathrm{ml}$ ) and lactic acid (7.5\%). All these three strains were selected for bread preparation.

From the results, it is evident that $\mathrm{T}_{2}$ treatment i.e. $50 \%$ Yeast $+50 \%$ LAB performed better than $\mathrm{T}_{1}$ (conventional bread) in terms of the acceptability index (Table 2). The $\mathrm{T}_{2}$ sourbread scored higher values in all the sensory parameters than the traditional bread. That means, by using only $50 \%$ population from the commercial yeast culture and the remaining $50 \%$ from the LAB consortium, bread could be produced whose acceptability level is higher than the currently produced bread. Similar observations were also made by Deshpande et al. (2013). They prepared sourdough bread using selected lactic acid bacterial cultures. They obtained a nutritionally superior sourdough bread using Lactobacillus brevis and L. palntarum along with the yeast. Superior quality bread was produced by using a mixture of yeast and $\mathrm{LAB}$ by others also
(Martinez-Anaya and Devesa., 2000). Proteolysis in sourdoughs has been reported to be higher than in yeasted doughs. LAB is known to improve taste and flavour of fermented products via proteolysis and lipolysis activities which cause production of aromatic compounds (acetate, ethanol, di acetyl and acetaldehyde, 3-methyl-1-butanol, 2-phenylethanol) (Galle et al., 2011). EPS is known to improve the volume, texture, and shelf life of bread (Zuzana et al., 2009). Pérez-Chabela et al. (2012) observed that Propioni bacterium acidilacti UAM15c and Leuconostoc plantarum UAM10a secreted exopolysaccharides which was related to high moisture stability and better textural properties, as compared with non-inoculated samples.

Nutritionally, the bread prepared using 50 per cent $\mathrm{LAB}$ and 50 per cent yeast cells was superior in that it possessed the least fat and higher ash content (Table 3 ). It is known that the low $\mathrm{pH}$ values associated with microbiologically acidified wheat dough leads to solubilization of the phytate complex, thus increasing mineral bioavailability, accounting to higher ash content (Larsson and Sandberg, 1991). The improvement in the mineral availability of sourdough baked goods has also been reported by Lopez et al. (2003). Oral administration of Lactobacillus gasseri NT strain reduced fat synthesis in adipose tissue, suggesting its potential to prevent the development of obesity

Table 1. Testing of Lactic acid bacterial isolates for functional traits.

\begin{tabular}{ccccc}
\hline $\begin{array}{c}\text { S. } \text { N. } \\
\text { Strain code } \\
\text { no. }\end{array}$ & $\begin{array}{c}\mathbf{C O}_{\mathbf{2}} \\
\text { production }\end{array}$ & $\begin{array}{c}\text { Lactic acid } \\
\text { production } \\
(\boldsymbol{\%})\end{array}$ & $\begin{array}{c}\text { EPS } \\
\text { production } \\
(\boldsymbol{\mu} \text { / } \mathbf{m l})\end{array}$ \\
\hline 1 & LAB 04 & + & 6.20 & 66.50 \\
2 & LAB 05 & - & 5.70 & 46.25 \\
3 & LAB 10 & + & 6.40 & 50.16 \\
4 & LAB 45 & - & 7.90 & 69.83 \\
5 & LAB 46 & + & 7.00 & 60.16 \\
6 & LAB 48 & + & 6.70 & 50.16 \\
7 & LAB 49 & + & 5.90 & 81.70 \\
8 & LAB 50 & + & 7.60 & 81.50 \\
9 & LAB 51 & + & 6.00 & 65.41 \\
10 & LAB 60 & - & 7.30 & 25.10 \\
11 & LAB 63 & + & 7.60 & 58.16 \\
12 & LAB 65 & + & 5.90 & 50.16 \\
13 & LAB 68 & + & 7.00 & 34.16 \\
14 & LAB 72 & + & 8.30 & 76.50 \\
15 & LAB 74 & + & 7.50 & 74.50 \\
16 & LAB 75 & - & 7.20 & 53.83 \\
17 & LAB 76 & + & 7.70 & 61.83 \\
18 & LAB 77 & - & 7.70 & 61.25 \\
19 & LAB 82 & - & 7.10 & 44.83 \\
20 & LAB 83 & + & 7.30 & 72.10 \\
21 & LAB 89 & - & 7.40 & 62.75 \\
22 & LAB 91 & + & 7.00 & 49.58 \\
\hline & & & & \\
\hline
\end{tabular}


Table 2. Sensory evaluation of four different breads prepared.

\begin{tabular}{clcccc}
\hline S. N. & \multicolumn{1}{c}{ Particulars } & \multicolumn{3}{c}{ Treatments } \\
\cline { 3 - 6 } & & $\mathbf{T}_{\mathbf{1}} \mathbf{- 1 0 0 \%} \mathbf{Y}$ & $\mathbf{T}_{\mathbf{2}} \mathbf{- 5 0 \%} \mathbf{Y :} \mathbf{5 0 \%} \mathbf{L}$ & $\mathbf{T}_{\mathbf{3}} \mathbf{- 5 0 \%} \mathbf{~ Y}$ & $\mathbf{T}_{\mathbf{4}} \mathbf{- 1 0 0 \%} \mathbf{~ Y : ~ 5 0 \% ~ L}$ \\
\hline 1 & Color of crumb & 7.22 & 7.42 & 7.07 & 7.25 \\
2 & Color of crust & 7.04 & 7.54 & 6.98 & 7.24 \\
3 & Texture of crumb & 7.02 & 7.31 & 6.90 & 7.25 \\
4 & Texture of crust & 6.95 & 7.44 & 7.02 & 7.15 \\
5 & Appearance & 7.12 & 7.38 & 7.00 & 7.32 \\
6 & Flavor & 7.00 & 7.10 & 6.95 & 7.14 \\
7 & Taste & 6.87 & 7.30 & 6.82 & 7.18 \\
8 & Overall acceptability & 7.05 & 7.34 & 6.98 & 7.51 \\
9 & Total score & 56.27 & 58.83 & 55.72 & 58.04 \\
10 & Acceptability index (\%) & 78.15 & 81.70 & 77.38 & 80.61 \\
\hline
\end{tabular}

Y- Yeast; L- LAB strains

Table 3. Nutritional composition of bread prepared using LAB and yeast cultures.

\begin{tabular}{llccccc}
\hline S. N. & Treatments & Moisture (\%) & Ash (\%) & Protei (\%) & Fat (\%) & Crude Fiber (\%) \\
\hline 1 & $100 \%$ Y & 32.52 & 6.20 & 14.16 & 8.60 & ND \\
2 & $50(y): 50 \%$ (L) & 30.68 & 7.70 & 10.15 & 7.68 & ND \\
3 & $50 \%$ Y & 26.61 & 4.55 & 10.15 & 10.84 & ND \\
4 & 100\%(Y):50\% (L) & 28.01 & 1.50 & 10.32 & 9.86 & ND \\
& CD at 1\% & 1.34 & 0.18 & 1.45 & 0.84 & \\
& S Em & 0.28 & 0.04 & 0.31 & 0.18 & \\
\hline
\end{tabular}

Y- Yeast; L- LAB strains; ND- Not detected

(Yonejima et al., 2013).

\section{Conclusion}

Thus, the results of the present study have indicated that the sourbread prepared using yeast and LAB cultures (1:1) were superior in textural characteristics, flavor, appearance and even taste. It contained enough protein $(10.15 \%)$ and the least fat value $(7.68 \%)$. It scored the highest acceptability index of 81.70.

\section{REFERENCES}

AACC, (2000). Approved Methods of the American Association of Cereal Chemists, $10^{\text {th }}$ Edition, AACC, St. Paul. MN, USA.

Deshpande, H.W., Hashmi, S.I. and Pathan, A. (2013). Effect of lactobacilli on nutritional quality of wheat brewad. Bioinfolet, 10:162-164.

Diop M.B., Dibois-Dauphin R., Tine, E, Jacqueline, A.N. and Thonart, P (2007). Bacteriocin producers from traditional food products. Biotechnol. Agron. Soc. Environ., 11:275-281.

Galle, S., Schwab, C., Arendt, E.K., and Gänzle, M.G. (2011). Structural and rheological characterization of heteropolysaccharides produced by lactic acid bacteria in wheat and sorghum sourdough. Food Microbiology, 28(3), 547-553.

Garcia, C.M. and Marshall, V. (1991). Polymer production by Lactobacillus delbrueckii ssp. bulgaricus. J. Appl. Bacteriol., , 70: 325-328.

Larsson, M., Sandberg, A.S. (1991). Phytate reduction in bread containing oat flour, oat brand, or rye bran. $J$. Cereal Sci., 14(2):141-149.
Lopez H.W., Ouvry A., Bervas E., Guy C., Messager A., Demigne C. and Remesy, C. (2000), Strains of lactic acid bacteria isolated from sour doughs degrade phytate and improve calcium and magnesium solubility from whole wheat flour. J. Agr. Food Chem., 48: 2281 -2285 .

Lopez, H.W, Duclos, V., Coudray, C., Krespine, V., Feillet-Coudray, C., Messager, A., Demigne, C., Remesy, C. (2003). Making bread with sourdough improves mineral bioavailability from reconstituted whole wheat flour in rats. Nutrition, 19: 524-530.

Martinez-Anaya, M.A. and Devesa, A. (2000). Influence of enzymes in sourdough wheat breadmaking. Changes in pentosans. Food Sci. Technol. Internl., , 6: 109-116.

Meilgaard, M., Civile, G.V. and Carr, B.T. (2007). Sensory Evaluation Techniques 4th Edition. Florida, USA: CRC Press.1-464.

Paola Lavermicocca, Francesca Valerio and Marco Gobbetti. (2000). Purification and characterization of novel antifungal compounds from the sourdough Lactobacillus plantarum strain 21B. Appl. Environ. Microbiol., 66: 4084-4090.

Pérez-Chabela, M.L., Lara-Labastida, R., Rodriguez Huezo, M.E. and Tosaus, A. (2012). Effect of spray drying encapsulation of thermotolerant lactic acid bacteria on meat batters properties. Food Bioprocess Technol., 22: 12-18.

Petra Gereková, Zuzana Petruláková, Ernest Šturdík, (2011). Importance of lactobacilli for bread-making industry. Acta Chimica Slovaca, 4:118-135.

Tieking, M, Gänzle M.G. (2005). Exopolysaccharides from cereal associated lactobacilli. Trends Food Sci. Technol., 16:79-84. 
Yonejima, Y. Ushida, K. and Mori Y. (2013). Effect of lactic acid on lipid metabolism and fat synthesis in mice fed with a high fat diet. Biosci. Microbiota Food Health, 32: 51-58.

Zuzana, P., Hybenová, E., Mikušová, L., Gereková, P., Kocková, M. and Šturdík, E. (2009). The effect of lactobacilli starter culture on quality of bread. Acta Chimica Slovaca, 2: 120 - 128.

Zuniga, M., Pardo, I. and Ferrer, S. (1993). An improved medium for distinguishing between homofermentative and heterofermentative lactic acid bacteria. Interntl. J. Food Microbiol., 18: 37-42. 